\title{
Revisão bibliográfica: reutilização de resíduos da construção e demolição na indústria da construção civil
}

\section{(Literature review: reuse of construction and demolition waste in the construction industry)}

\author{
L. L. Brasileiro ${ }^{1}$, J. M. E. Matos ${ }^{2}$ \\ ${ }^{1}$ Centro de Tecnologia - CT, ${ }^{2}$ Centro de Ciências da Natureza - CCN, Departamento de Química, \\ LIMAv, Universidade Federal do Piauí, Teresina, PI, 64049-550 \\ luzanaleite@hotmail.com,jmematos@ufpi.edu.br
}

\begin{abstract}
Resumo
As questões ambientais têm ocupado cada vez mais espaço nas legislações dos países, devido à grande geração de resíduos, oriundos principalmente, da indústria da construção civil. Para qualquer país, não tem como haver crescimento, sem que a indústria da construção o acompanhe. Crescimento este, que gera grandes impactos ambientais, desde a extração de recursos naturais para a produção de insumos, até a produção de resíduos, que são dispostos no meio ambiente sem nenhum controle. Este artigo expõe pesquisas que retratam a preocupação quanto à geração dos resíduos provenientes da indústria da construção não somente no Brasil, mas em todo o mundo. Pesquisadores de todo o planeta disponibilizam dados quanto à quantidade de RCD gerado, legislações empregadas com o intuito de minimizar e prevenir a geração de RCD e aplicabilidades dos resíduos reciclados nos mais diversos ramos do setor construtivo, de forma a promover o seu retorno à cadeia da construção. Dados estes, que foram apresentados neste trabalho, com o intuito de "acordar" o Brasil, para a nova ordem mundial, em que a palavra reciclar, não mais será uma opção, e sim, rotina de cada brasileiro.
\end{abstract}

Palavras-chave: meio ambiente, RCD, construção, reciclagem.

Abstract

Environmental issues have occupied more and more space in the laws of countries due to the large generation of waste, coming mainly from the construction industry. For any country, there can be no growth without the parallel growth in the construction industry. This growth generates large environmental impacts, from the extraction of natural resources for the production of raw materials through production of waste that are sometimes discharged into the environment without any control. This article presents research that portrays concern over the generation of waste from the construction industry not only in Brazil but worldwide. Researchers from around the world provide information about the amount of RCD generated, laws employed in order to minimize and prevent the generation of RCD and applicability of recycled waste in the most diverse branches of the construction sector in order to promote its return to the construction chain. The data, which were presented in this paper, is intended to "wake up" Brazil, for the new world order, where the word recycle, will no longer be an option, but rather, routine in the life of every Brazilian.

Keywords: environment, RCD, construction, recycling.

\section{INTRODUÇÃO}

A construção civil é uma das atividades mais antigas que se tem conhecimento e desde os primórdios da humanidade foi executada de forma artesanal, gerando como subproduto, grande quantidade de resíduos de diversas naturezas. É também responsável pelo consumo excessivo de recursos naturais provenientes de fontes não-renováveis $[1,2]$.

Hoje, a Indústria da Construção Civil é reconhecida como uma das mais importantes atividades para o desenvolvimento econômico e social, mas por outro lado, comporta-se ainda como grande geradora de impactos ambientais [3]. A cadeia produtiva da construção civil consome entre 20 e $50 \%$ dos recursos naturais de todo o planeta [4].

As atividades de construção demandam uma notável quantidade de materiais inertes, tais como areia e cascalho, que usualmente são fornecidos por meio da extração de sedimentos aluviais. A extração desses sedimentos modifica o perfil dos rios e o seu equilíbrio, além de introduzir problemas ambientais como modificação em sua estrutura hidrológica e hidrogeológica. A extração de material inerte de formações rochosas em área acidentadas e montanhosas também é uma danosa atividade ao meio-ambiente, uma vez que altera a paisagem e provoca problemas de instabilidade $[5,6]$.

Com a urbanização acelerada, que resultou no rápido adensamento das cidades, e, por conseguinte, o crescimento das atividades do setor construtivo, além da larga exploração dos recursos naturais, a geração de resíduos da construção e demolição (RCD) alcançou índices alarmantes, produto do 
desperdício nas obras de construções, reformas e demolições [7]. Esses resíduos representam aproximadamente, de 20 a $30 \%$ do fluxo de resíduos sólidos gerados pelas cidades dos países desenvolvidos, sendo que nos demais pode alcançar índices bem maiores [8, 9]. Segundo Pinto [10], nas cidades brasileiras o RCD representa de 41 a $70 \%$ da massa total de resíduos sólidos urbanos (RSU). Para Cabral et al. [6], o RCD constitui uma importante parcela do RSU, correspondendo em torno de 50\%, enquanto que para Silva e Fernandes [11], em alguns municípios, representa $60 \%$ do montante de RSU. Um ponto que demonstra a relevância dos RCD e a sua crescente participação no total de RSU, é o caso da cidade de Salvador, que no período de 1990 a 2000, o RCD aumentou a sua participação na composição do RSU de 4,4\% para 49,8\%, ou ainda Fortaleza, que com 2,5 milhões de habitantes, só em 2009, produziu em torno de $3.200 \mathrm{~m}^{3}$ de RCD por dia, correspondendo a uma taxa de geração de 0,56 toneladas habitante ${ }^{-1}$ ano $^{-1}[6,12]$. A falta de gerenciamento desses resíduos afeta as cidades nos aspectos sociais, econômicos e ambientais. Desta forma, ações no sentido de enfrentar este problema tiveram início no final da década de 1980 em alguns países da Europa, enquanto que no Brasil, somente no início do século XXI. O Brasil, até 2002 não tinha políticas públicas para os resíduos gerados pelo setor da construção civil. Em 05 de Julho de 2002 entrou em vigor a Resolução $n^{0} 307$ do Conselho Nacional de Meio Ambiente (CONAMA), a qual estabelece diretrizes, critérios e procedimentos para a gestão dos resíduos da construção civil, visando proporcionar benefícios de ordem social, econômica e ambiental. Em 16 de Agosto de 2004, entrou em vigor a resolução $\mathrm{n}^{\circ} 348$ do CONAMA que altera o art. $3^{\circ}$, item IV, da Resolução $n^{\circ} 307$ [2]. Unindo força à Resolução n 307 do CONAMA, no ano de 2010 o Brasil aprovou a Política Nacional de Resíduos Sólidos (PNRS), por intermédio da Lei $\mathrm{n}^{\mathrm{o}} 12.305$ de 2 de Agosto de 2010, a qual define a forma como o país deve dispor os seus resíduos, incentivando a reciclagem e a sustentabilidade. A Lei se baseia no princípio de responsabilidade compartilhada (art. $3^{\circ}$ - inciso XVII), pois a maioria dos problemas ambientais vem seguida de questões sociais e econômicas, que acabam por impactar grande parte da sociedade, ou seja, o problema ambiental é compartilhado. Desta forma, todos os agentes envolvidos na fabricação, distribuição, venda e consumo são responsáveis pelos seus resíduos. A Lei estabelece também o fechamento dos conhecidos "lixões" (local em que o lixo é depositado sem tratamento ou separação) até o ano de 2014. Para os aterros sanitários somente serão destinados os rejeitos, material este composto quase na sua totalidade por matéria orgânica. Desta forma, a palavra do momento é RECICLAR. Se houver uma efetiva fiscalização da lei e o fechamento dos "lixões", o tratamento e a reciclagem de resíduos sólidos como papel, plásticos, metal e inclusive, dos resíduos sólidos da construção e demolição, poderá ter alta nos lucros. Geralmente, a maioria dos resíduos gerados nos canteiros de obras e de demolição é composta por restos de argamassas, tijolo, alvenaria, concreto, cerâmica, gesso, madeira, metais e etc., que são descartados em aterros sanitários devido a ausência de mercados para suas formas recicladas [13]. O RCD serve de matéria-prima para agregados de ótima qualidade, podendo ser utilizados num leque de variedades de processos construtivos: confecção de tijolos, blocos pré-moldados, meio-fio, calçadas, argamassa de revestimento, camadas de base e sub-base, pavimentos, entre outros.

$\mathrm{Na}$ maioria dos países, emprega-se largamente o revestimento asfáltico como camada de pavimentos rodoviários e urbanos. No Brasil, mais de $95 \%$ das estradas pavimentadas são de revestimento asfáltico, além de ser também utilizado em grande parte das vias urbanas [14]. O agregado que é utilizado nas misturas asfálticas é obtido da exploração de jazidas e provém da britagem de rochas como o basalto, granito, gnaisse, calcário, entre outros tipos, os quais são transformados em pedra britada com vários tamanhos e de graduação específica [15]. A construção e a manutenção dos pavimentos asfálticos requerem grandes quantidades de agregados, os quais normalmente são responsáveis por mais de $90 \%$, em peso, das misturas asfálticas [16].

A produção e venda de ligante asfáltico pela Petrobras para fins de aplicação em obras de infraestrutura no Brasil registraram recorde em 2010, tendo sido produzido 2,763 milhões de toneladas de asfalto, um crescimento de $32 \%$ em relação ao ano de 2009 [17], o que leva a estimar um consumo de aproximadamente 35 milhões de toneladas de agregados extraídos das reservas naturais somente para misturas a quente. Por outro lado, em 2011, a coleta de RCD aumentou $7,2 \%$ em relação a 2010 , chegando a 33 milhões de toneladas em todo o Brasil, executada apenas pelos órgãos públicos, não incluindo o RCD coletado por serviços privados, os quais constituem a grande maioria do total de RCD gerado [18]. $\mathrm{O}$ crescente consumo de agregados naturais juntamente com a crescente produção de RCD e as diretrizes da resolução $n^{\circ}$ 307 do CONAMA e da PNRS, têm levado à consolidação de técnicas de reciclagem. O uso de agregados reciclados em misturas asfálticas tem sido um tema interessante para a proteção do ambiente e desenvolvimento sustentável [15]. Desta forma, este trabalho de revisão bibliográfica versa sobre a reutilização de resíduos da construção e demolição na própria indústria da construção civil sob a forma de agregados reciclados. $\mathrm{O}$ artigo explana à cerca das disparidades da indústria da construção com os conceitos de sustentabilidade, da quantidade de RCD gerado no mundo, das legislações implantadas com o intuito de minimizar os impactos ambientais gerados pelo RCD, da reciclagem do RCD e sua aplicabilidade nos mais diversos ramos da construção civil, inclusive nos pavimentos flexíveis.

\section{A indústria da construção civil $x$ sustentabilidade}

Desde a Pré-História o homem tem transformado matérias-primas (pedras, barro, peles, lã, trigo, etc.) em produtos úteis à sua sobrevivência. Trata-se de um antigo método de transformação a que se denominou artesanato, na qual, com o uso de instrumentos transformava a matériaprima até chegar ao produto final [19]. 
Nos séculos XVIII e XIX, houve o início da Revolução Industrial em algumas cidades européias e americanas, e a consequente criação de fábricas nas cidades. A população de muitas cidades começou a aumentar rapidamente, recebendo milhares de pessoas vindas dos campos, abandonando trabalhos nas áreas rurais, para trabalhar na indústria. Este fato gerou imensas aglomerações humanas que passaram a consumir uma grande quantidade de energia, alimentos e espaço, ocasionando em cidades superlotadas, barulhentas, sujas e sem nenhum saneamento. Esses grandes aglomerados humanos originaram os mais variados problemas de urbanização: abastecimento de água, canalização de esgotos, criação e fornecimento de mercadorias, modernização de estradas, fornecimento de iluminação, fundação de escolas, construção de habitações e etc. [19].

Segundo o Worldwatch Institute - Beyond Malthus: Sixteen Dimensions of the Population Problem -, em 1960, somente $34 \%$ da população mundial, o que corresponde a 300 milhões de pessoas, residia em cidades. Em apenas 50 anos, esse percentual subiu para $52 \%$, ou seja, cerca de 3,6 bilhões de pessoas estavam vivendo nas cidades nos anos 2000. No Brasil, já somos cerca de $84 \%$ da população vivendo nas cidades, e segundo o IBGE, com previsão para $90 \%$ em 2020 [20].

Os impactos ecológicos não eram considerados nas sociedades primitivas, pois a produção de resíduos era pequena e a assimilação ambiental era grande. Somente após o desenvolvimento tecnológico da revolução industrial no mundo, é que esta preocupação veio à tona. A partir desta constatação, começam a surgir as primeiras preocupações e questionamentos relativos ao efeito estufa e consequentemente o aumento do consumo de energia, a destruição da camada de ozônio, a poluição do ar e as chuvas ácidas, o consumo desmedido de matérias-primas não renováveis, a geração de resíduos, dentre outros. E é justamente a partir daí que surge o termo desenvolvimento sustentável.

Desta forma, desenvolvimento sustentável pode ser definido como aquele que "permite atender às necessidades básicas de toda a população e garanta a todos a oportunidade de satisfazer suas aspirações para uma vida melhor sem, no entanto, comprometer a habilidade das gerações futuras atenderem suas próprias necessidades" [21].

Com relação ao desenvolvimento sustentável, a implicação mais imediata é a necessidade de se produzir a maior quantidade de bens com a menor quantidade de recursos naturais e a menor poluição, ou seja, o desenvolvimento econômico deverá ser desvinculado da geração de impactos ambientais.

Para conseguir esta desvinculação são necessárias várias ações [22]: redução do consumo de matérias primas, que pode ser obtido pela redução e reciclagem de resíduos, aperfeiçoamento de projetos, substituição dos materiais tradicionais por outros mais eficientes e aumento da durabilidade dos produtos; redução do consumo de energia (especialmente a produzida pela queima de combustíveis não renováveis); redução global da poluição (incluindo resíduos).
A indústria da construção civil é a atividade humana com maior impacto sobre o meio ambiente. Estima-se que 50\% dos recursos naturais extraídos estão relacionados à atividade de construção. É ainda, a responsável por aproximadamente $15 \%$ do produto interno bruto (PIB) brasileiro, com investimentos que ultrapassam $\mathrm{R} \$ 90$ milhões por ano, geração de 62 empregos indiretos para cada 100 empregos diretos, contribuindo para a redução do déficit habitacional e da infraestrutura, indispensável ao progresso [22, 23]. É natural que, tendo um papel tão representativo na economia nacional, a construção civil seja também um dos grandes vilões ambientais. É o maior consumidor de matérias-primas (até $50 \%$ do total de recursos consumidos pela sociedade), envolve processos com grande consumo de energia (cerca de $80 \%$ da energia utilizada na produção de um edifício é consumida na produção e transporte de materiais), gera poluição em quase todos seus processos (da extração de matérias-primas à produção de produtos como cimento e concreto), e até mesmo na fase de uso dos edifícios os impactos ambientais são inúmeros (dados mostram que o volume de recursos consumido na fase de manutenção da edificação é praticamente igual ao consumido durante a construção) $[2,4,5,7,22]$.

Tendo em mente a grandiosidade da cadeia produtiva da indústria da construção civil, fica claro que não é possível alcançar o desenvolvimento sustentável sem que a indústria da construção também se torne sustentável.

Para minimizar os impactos ambientais da indústria da construção, Kilbert [24] propôs os seguintes princípios:

I. Minimizar o consumo de recursos: gastar mais tempo na fase de planejamento e projetos para otimizar a utilização de materiais e minimizar a produção de resíduos;

II. Maximizar a reutilização de recursos: reutilizar componentes que ainda possam desempenhar a função para a qual foram produzidos, ou mesmo serem utilizados em outra função;

III. Usar recursos renováveis e recicláveis: optar por materiais recicláveis ou cujas fontes de matéria-prima sejam renováveis;

IV. Proteger o meio-ambiente: evitar o uso de materiais cuja extração de matéria-prima cause danos ambientais: aproveitar os recursos naturais para iluminação e ventilação, reusar águas servidas, etc.;

V. Criar um ambiente saudável e não tóxico: evitar utilização de materiais que podem causar danos tanto ao meio ambiente quanto aos usuários;

VI. Buscar a qualidade na criação do ambiente construído: projetar utilizando técnicas que permitam uma construção mais econômica, menos poluente e que impacte menos agressivamente no meio-ambiente.

Com base no que foi apresentado até aqui, pode-se concluir que a sustentabilidade da indústria da construção ainda é uma meta distante e difícil de ser alcançada. No entanto, vale ressaltar que o primeiro passo rumo à sustentabilidade já foi dado com a implantação de leis e resoluções que demonstram uma efetiva preocupação com a gestão dos resíduos, e hoje grande parte dos envolvidos 
na cadeia produtiva já estão conscientes de que mudanças são necessárias para que o objetivo de uma indústria da construção sustentável seja alcançado.

\section{A geração de $R C D$}

Segundo John, citado por Santos [25], a geração de RCD é anterior ao início de qualquer obra ou serviço, se observarmos que a produção de insumos para a construção civil, além de consumir recursos naturais também produz resíduos. O RCD pode ser oriundo de obras viárias, material de escavação, demolição de edificações, construções, renovação de edifícios, limpeza de terrenos [26] e até mesmo de catástrofes naturais (tsunamis, tornados, terremotos, etc.) ou artificiais (incêndios, desabamentos, bombardeios, etc.) [27].

Um ponto que demonstra a relevância dos resíduos de construção e demolição é a sua crescente participação no total dos RSU [12]. Na Malásia, esses resíduos correspondem, juntamente aos resíduos industriais, a $28 \%$ do total dos RSU, enquanto que o resíduo doméstico totaliza $37 \%$ do total $[27,28]$. Na Austrália, em 204, os resíduos da indústria da construção civil correspondiam a aproximadamente $37 \%$ do total de resíduos sólidos produzidos no país [28]. Em Hong Kong, no Kuwait e no Reino Unido, esse tipo de resíduo corresponde a 38,58 e $60 \%$, respectivamente [27, 29-32] de todo o resíduo sólido produzido, enquanto que, nos Estados Unidos, estima-se que os RCD correspondem de 10 a $30 \%$ do total de resíduos gerados no país [33]. Para se ter uma ideia de grandeza da geração desses resíduos, no Reino Unido este setor produz em torno de 109 milhões de toneladas por ano, sendo que esta quantidade equivale a $66 \%$ dos 165 milhões de toneladas de agregados naturais consumidos anualmente na construção civil [27, 31]. Estima-se também, que, aproximadamente, 200 milhões de toneladas de resíduos de concreto são atualmente produzidos anualmente no continente da China [34]. Enquanto que em Taiwan, cerca de 14 milhões de toneladas de RCD é gerada a cada ano [35]. Em Hong Kong, de acordo com dados do Departamento de Proteção Ambiental a partir de 2009, a cidade passou a produzir mais de 15 milhões de toneladas de RCD por ano $[26,36]$.

Como em todo processo industrial, o uso dos insumos da indústria da construção civil gera resíduos em grande escala, que necessitam ser gerenciados [6]. O macrocomplexo da indústria da construção civil é responsável por $40 \%$ dos resíduos gerados na economia [37]. Na União Europeia (UE), em torno de 850 milhões de toneladas de RCD são geradas anualmente. Isso representa um total de $31 \%$ dos resíduos gerados na UE [38], 60 milhões nos Estados Unidos e 12 milhões somente no Japão [37, 38]. Esses resíduos representam aproximadamente, de 20 a $30 \%$ do fluxo de resíduos sólidos gerados pelas cidades dos países desenvolvidos, sendo que nos demais, pode alcançar índices bem maiores $[9,39]$.

No Brasil, a tarefa de quantificação é ainda mais difícil, diferentemente de outros países, pois uma importante fonte na geração de RCD são os geradores informais, para os quais dados estatísticos estão indisponíveis e podem representar uma parcela importante dos RCD gerados em um município [40]. Porém, em algumas grandes cidades, como São Paulo, Rio de Janeiro e Salvador, têm estimativas específicas. Nestas três cidades, a média de produção diária de RCD foi de $0,49 \mathrm{~kg}$ por habitante, correspondendo a cerca de $31 \%$ dos resíduos recolhidos nacionalmente [41]. Segundo a ABRELPE (Associação Brasileira de Empresas de Limpeza Pública e resíduos especiais) [41], só no ano de 2013, o RCD produzido nas cidades brasileiras representa cerca de $48 \%$ da massa total de RSU gerados neste ano. Para Cabral [6] o RCD constitui uma importante parcela do RSU, correspondendo em torno de 50\%, enquanto que para Silva e Fernandes [11], em alguns municípios, representa $60 \%$ do montante de RSU. A ABRELPE divulgou em seu Panorama de Resíduos Sólidos no Brasil 2013, uma estimativa feita para os anos de 2010 e 2013 do total de RCD coletado no Brasil e nas suas cinco regiões [41]. Todos os dados referemse apenas à coleta executada pelo serviço público, o qual usualmente limita-se a recolher os resíduos desta natureza lançados em logradouros públicos, pois a responsabilidade da coleta e destino final destes resíduos é de seu gerador. Portanto, de maneira geral, as projeções sobre tais resíduos não incluem os RCD oriundos de demolições e construções coletados por serviços privados, os quais constituem a grande maioria do total de RCD gerado. Observa-se pela Fig. 1 que, em 2011, a coleta de RCD aumentou 7,2\% em relação ao ano de 2010, em 2012, a coleta RCD aumentou $5,0 \%$ em relação ao ano de 2011, e que em 2013, a coleta RCD aumentou $10,4 \%$ em relação ao ano de 2012 , chegando

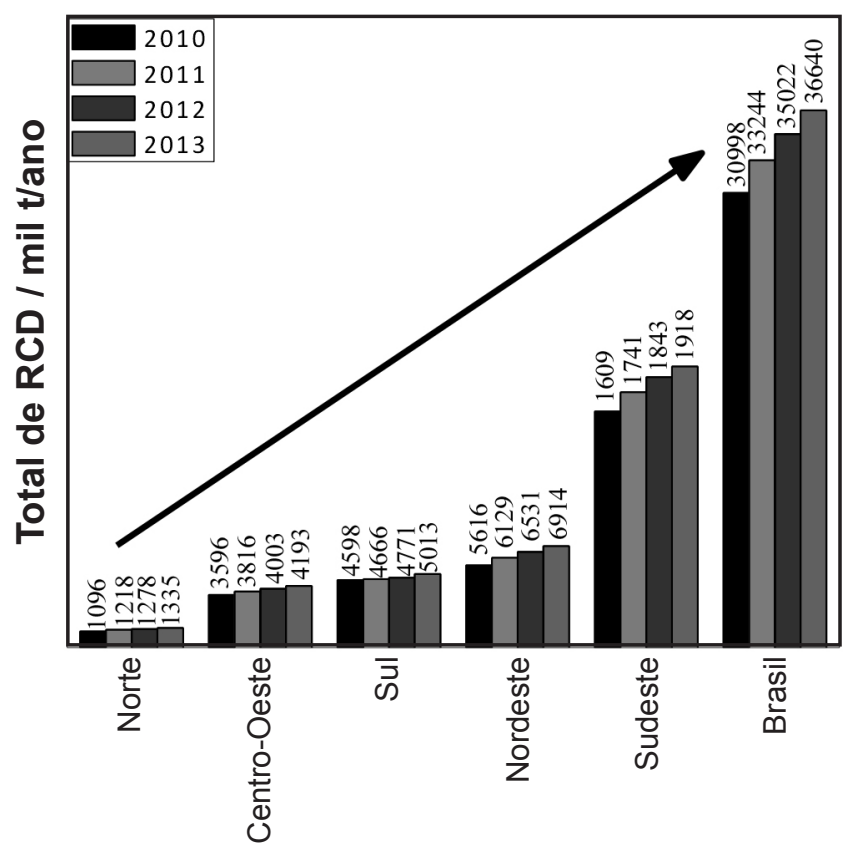

Figura 1: Total de RCD coletado no Brasil e por região do Brasil [41].

[Figure I: Total CDW collected in Brazil and by region of Brazil [41].] 
a aproximadamente 37 milhões de toneladas em todo o Brasil, executadas apenas pelos órgãos públicos, dados estes bastante significativos.

Os problemas ambientais resultantes da disposição do RCD são motivos de preocupação por causa dos impactos que os locais de disposição ilegais (que ocorrem rotineiramente) têm sobre as cidades e seu ambiente, além de aumentar, rapidamente, as áreas de aterro sanitário público em municípios em que o mesmo não possui nenhuma aplicabilidade. Esta questão tem sido amplamente debatida e tem estimulado o interesse por soluções ambientalmente sustentáveis. Neste contexto, a legislação ambiental tornouse mais rigorosa, com uma tendência a fazer, geradores de resíduos, responsáveis pela destinação do seu resíduo, levando à adoção de técnicas de minimização do desperdício e políticas de reciclagem.

\section{Legislações à cerca do gerenciamento de resíduos sólidos}

John [42] afirmou: "Nenhuma sociedade poderá atingir o desenvolvimento sustentável sem que a construção civil, que lhe dá suporte, passe por profundas transformações".

A maioria das ferramentas usadas nas políticas públicas de minimização de RCD pode ser implantada em vários estágios do processo de construção, projeto, demolição e manejo de resíduos. Murakami [43] apud Schneider e Philippi [44] citam alguns dos melhores exemplos de políticas vigentes no mundo, segundo pesquisa realizada pelo WPPPC (Working Party Pollution Prevention and Control) of the Environment Policy Committee of the Organization for Economic Cooperation and Development (OECD).

- Incentivo ao uso de materiais de construção reciclados e recicláveis: a Alemanha, a Coréia e o Japão têm leis com recomendações gerais para estimular o uso de materiais recicláveis e reciclados;

- Cobrança de preços elevados para a deposição de RCD em aterros: amplamente utilizada na Dinamarca, Inglaterra, República Checa, Itália e França. A cobrança funciona como incentivo para a reciclagem dos resíduos. Em cinco países europeus é proibida a deposição de algumas categorias de RCD em aterros. Estas proibições variam de país para país, mas o objetivo principal é prevenir a deposição, no solo, de materiais recicláveis e reutilizáveis;

- Triagem obrigatória de RCD em obras e entrega obrigatória em unidades de reciclagem: sete países europeus e o Japão introduziram esse importante instrumento de política regulatória;

- Demolição controlada: em quatro países europeus é necessário apresentar às autoridades documentação de como o RCD serão tratados antes da demolição das edificações. Na Suécia, por exemplo, o plano de gestão deve acompanhar a documentação para demolição da edificação, o qual deve ser aprovado pelas autoridades. Neste deve estar descrita a destinação de cada um dos materiais resultantes;

- Taxação de matérias-primas oriundas da atividade de mineração: é também usada como forma de estimular o uso de materiais provenientes dos RCD. Na Dinamarca a taxa sobre recursos naturais é imposta a pedreiras e na Suécia à exploração dos bens minerais por escavação. Na Inglaterra são taxadas a areia, cascalho e pedras;

- Subsídios financeiros para unidades de tratamento de RCD: a Inglaterra subsidia a compra de equipamentos e a Bélgica investe em companhias de reciclagem que processam RCD; e

- Padrões para o uso de materiais reciclados: são utilizados na Alemanha e Holanda. Na Bélgica, foi desenvolvido um esquema de certificação voluntária para agregados reciclados, baseada em especificações técnicas estabelecidas pelas autoridades.

No Brasil, até o ano de 2002 não tinha políticas públicas para os resíduos gerados pelo setor da construção civil. Em 05 de Julho de 2002 entrou em vigor a Resolução ${ }^{\circ}$ 307 do CONAMA, a qual estabelece diretrizes, critérios e procedimentos para a gestão dos resíduos da construção civil, visando proporcionar benefícios de ordem social, econômica e ambiental. Em 16 de Agosto de 2004, entrou em vigor a resolução $n^{\circ} 348$ do CONAMA que altera o art. $3^{\circ}$, item IV, da Resolução $n^{\circ} 307$ [2]. Considerando-se que os resíduos dessa natureza representam um significativo percentual dos resíduos sólidos produzidos nas áreas urbanas e que a disposição de resíduos da construção civil em locais inadequados contribui para a degradação da qualidade ambiental, os Municípios são os responsáveis pela gestão e destinação ambientalmente correta de tais resíduos, buscando a efetiva redução dos impactos ambientais.

Segundo as Resoluções $n^{\circ} 307$ e no 348 os resíduos da construção civil são classificados em quatro classes:

I - Classe A - são os resíduos reutilizáveis ou recicláveis como agregados, tais como: a) de construção, demolição, reformas e reparos de pavimentação e de outras obras de infraestrutura, inclusive solos provenientes de terraplanagem; b) de construção, demolição, reformas e reparos de edificações: componentes cerâmicos (tijolos, blocos, telhas, placas de revestimento etc.), argamassa e concreto; c) de processo de fabricação ou demolição de peças pré-moldadas em concreto (blocos, tubos, meios-fios etc.) produzidas nos canteiros de obras; II - Classe B - são os resíduos recicláveis para outras destinações, tais como: plásticos, papel/papelão, metais, vidros, madeiras e outros; III - Classe $C$ - são os resíduos para os quais não foram desenvolvidas tecnologias ou aplicações economicamente viáveis que permitam a sua reciclagem/recuperação, tais como os produtos oriundos do gesso; IV - Classe D - são resíduos perigosos oriundos do processo de construção, tais como tintas, solventes, óleos e outros ou aqueles contaminados ou prejudiciais à saúde, oriundos de demolições, reformas e reparos de clínicas radiológicas, instalações industriais e outros, bem como telhas e demais objetos e materiais que contenham amianto ou outros produtos nocivos à saúde.

Esta resolução atribui responsabilidades tanto para o poder público quanto para a iniciativa privada. As empresas privadas de construção, que são grandes geradoras do resíduo Classe A, devem desenvolver projetos de gerenciamento 
específicos, por exemplo, triagem em canteiros de obras, incluindo o uso de transportadores cadastrados e área licenciadas para manejo e reciclagem. O poder público deve oferecer uma rede de coleta e destinação ambientalmente correta para os pequenos geradores, responsáveis por reformas e autoconstruções e incapazes de implementar a autogestão [45].

A publicação da resolução do CONAMA N 307 motivou alguns municípios a implantarem planos de gerenciamento. Contudo, de acordo com estudos realizados por Pinto [10], dos 5.565 municípios existentes no país [46], apenas 50 implantaram planos de gerenciamento. Um levantamento recente sobre usinas brasileiras de reciclagem de RCD mostrou que essas usinas, operando nas capacidades máximas, conseguiriam reciclar apenas cerca de $4,5 \%$ dos RCD gerados [5, 45, 47].

Dentre as dificuldades apontadas para a implantação dos planos de gerenciamento de RCD, Marques Neto [48] destaca a falta de recursos financeiros e a inexistência de corpo técnico qualificado nos quadros profissionais capazes de diagnosticar fontes geradoras e implementar ações, como a fiscalização [40, 45, 47].

Unindo força à Resolução n ${ }^{\circ} 307$ do CONAMA, no ano de 2010, o presidente Luís Inácio Lula da Silva sancionou a Lei $\mathrm{n}^{\mathrm{o}} 12.305$ de 02 de Agosto de 2010, após longos 21 anos de discussão no Congresso Nacional. A Lei se refere à Política Nacional de Resíduos Sólidos (PNRS), a qual define a forma como o país deve dispor os seus resíduos, incentivando a reciclagem e a sustentabilidade. A Lei se baseia no princípio de responsabilidade compartilhada (art. $3^{\circ}$ - inciso XVII), pois a maioria dos problemas ambientais vem seguida de questões sociais e econômicas que acabam por impactar grande parte da sociedade, ou seja, o problema ambiental também é compartilhado. Desta forma, todos os agentes envolvidos na fabricação, distribuição, venda e consumo são responsáveis pelos seus resíduos.

As principais diretrizes da PNRS são:

- Eliminação de áreas irregulares de disposição final de RCD ("bota-fora") em todo o território nacional;

- Implantação de áreas de transbordo e triagem, de reciclagem e de reservação adequada de $\mathrm{RCD}$ em todo o território nacional;

- Realização de inventário de resíduos de construção civil;

- Incremento das atividades de reutilização e reciclagem do RCD nos empreendimentos públicos e privados em todo o território nacional;

- Fomento a medidas de redução da geração de rejeitos e resíduos de construção civil em empreendimentos em todo o território nacional.

Uma das metas mais promissoras da PNRS é o fechamento dos conhecidos "lixões" (local onde o lixo é depositado sem tratamento ou separação), até o ano de 2014, sendo que a grande maioria dos municípios brasileiros não cumpriram esta determinação. Para os aterros sanitários municipais somente serão destinados os rejeitos, material este composto quase na sua totalidade por matéria orgânica.
O RCD deve ser destinado a aterros Classe A, onde o mesmo será reservado para usos futuros. Além disso, serão implantadas área de triagem, reutilização e reciclagem. Esperava-se que até 2014 houvesse a eliminação de 100\% das áreas de disposição irregular do RCD (Bota Fora).

Desta forma, o mercado da reciclagem atrelada aos resíduos da construção civil promete reverter o cenário atual nacional e atrelar poder econômico aos resíduos.

\section{A reciclagem de $R C D$}

Nos anos 80, em virtude da escassez de áreas para disposição final de RCD na Europa, a reciclagem e a minimização de resíduos passaram a ser objeto de atenção especial no setor da construção civil e diversas políticas públicas foram implementadas com esse objetivo [49]. Quanto ao total de CD, deve ser notado que no Brasil, são contabilizados apenas os resíduos lançados nos logradouros públicos, coletados pelos municípios [50].

Uma solução, que a cada dia ganha força entre os pesquisadores, é a reciclagem de RCD e sua reutilização na própria construção civil, como matéria-prima alternativa. Além de redução da superexploração de jazidas minerais para extração de recursos naturais não renováveis, há também, a carência de locais para a deposição desses resíduos, fazendo com que as distâncias entre os locais de demolição e as áreas de disposição sejam cada vez maiores, onerando os custos de transporte. A reciclagem de RCD contribui também para a ampliação da vida útil dos aterros, especialmente em grandes cidades, em que a construção civil é intensa e há escassez de área para deposição. Em cinco países europeus é proibida a deposição de algumas categorias de $\mathrm{RCD}$ em aterros. Estas proibições variam de país para país, mas o objetivo principal é prevenir a deposição no solo de materiais recicláveis e reutilizáveis [51]. Estes resíduos são compostos em sua maioria por restos de argamassa, tijolo, alvenaria, concreto, cerâmica, gesso, madeira, metais, etc., e, em maior parte, são considerados inertes [9]. A reciclagem de RCD traz benefícios econômicos e ambientais para as cidades em que é implantada. Além da diminuição dos custos de gerenciamento do resíduo, o custo do produto reciclado é bem menor que o agregado natural. Leite [52] citado por Costa [9] observa que se obtém uma economia de $67 \%$ em média, quando comparados os preços do agregado reciclado e do agregado natural. Segundo Pereira [53] citado por Coelho e de Brito [54], em Portugal, cerca de 76\% do RCD são depositados em aterros, $11 \%$ é reutilizado, $9 \%$ é reciclado e $4 \%$ incinerado. A realidade atual é clara: a quantidade de RCD reciclados/reutilizados (20\%) é pequena quando comparado com outros países, como o Reino Unido (52\%), a Holanda (92\%), a Bélgica (89\%), a Áustria (48\%) e a Dinamarca (81\%) [51]. A realidade de Portugal no quesito reciclagem ainda está muito aquém da Comunidade Européia (CE), que estabelece que, no ano de 2020, pelo menos $70 \%$ do RCD deve ser reutilizado/reciclado [54, 55]. Já na Irlanda, uma pequena parcela do RCD é utilizada como cobertura em aterros sanitários, sendo a maior parte 
depositada em aterros ilegais. Sabai [55] em sua pesquisa, afirma que na Tanzânia, o RCD não é reciclado e estudos sobre como este pode ser reciclado, especialmente em produtos de valor como materiais de construção, ainda são limitados. Enquanto que os Estados Unidos recicla até 70\% e a Alemanha até 90\% [55]. Para Duran, Lenihan e O'Regan [13], a viabilidade econômica do RCD é viável quando o custo de deposição em aterro exceder o custo de transporte para o centro de reciclagem e o custo de utilização do agregado primário exceder o custo do agregado reciclado.

No Brasil, estudos sobre a reciclagem de RCD datam de 1983 [56, 57], porém somente no final de 1995 as primeiras usinas de reciclagem começaram efetivamente a operar, em escala industrial [58]. Para Evangelista, Costa e Costa [59], citado por Silva e Fernandes [11], a reciclagem de RCD no Brasil encontra-se em atraso quando comparado aos países europeus. De acordo com o IBGE (2008) [60], dos 5.564 municípios brasileiros, 4.031 municípios $(72,45 \%)$ possuem "serviço de manejo dos resíduos de construção e demolição"; em 392 municípios (7,05\%) tem "existência e tipo de processamento dos resíduos", 124 (2,23\%) existe a "triagem simples dos resíduos de construção e demolição reaproveitáveis (classes A e B)", em 14 (0,25\%) existe "triagem e trituração simples dos resíduos classe A", em 20 $(0,36 \%)$ existe "triagem e trituração dos resíduos classe A, com classificação granulométrica dos agregados reciclados" e somente em 79 municípios $(1,42 \%)$ existe o programa de "reaproveitamento dos agregados produzidos na fabricação de componentes construtivos. Somente uma parte do RCD desses municípios é destinada às usinas de reciclagem, concluindo-se que a grande maioria dos RCD no Brasil não é reciclada.

Embora a reciclagem do RCD ainda não tenha se consolidado no âmbito das prefeituras municipais e nem da iniciativa privada, espera-se que a partir da entrada em vigor da Política Nacional de Resíduos Sólidos e estabelecimento de prazos para o alcance das metas, alguns municípios se organizem para uma efetiva política de gerenciamento do seu RSU, objetivando a reutilização e reciclagem, inclusive, do RCD, resíduo este que compõe entre 50 e $60 \%$ do RSU no Brasil.

\section{Aplicabilidade do $R C D$ reciclado}

A construção civil é um dos setores que apresenta maior potencial para absorver os resíduos sólidos. Exemplos de aplicações têm sido apresentados por diversos autores [47, 59, 61-74]. Dentre as várias possibilidades, a reciclagem de RCD pode ser aplicada para diversos fins, tais como: camadas de base e sub-base para pavimentação, coberturas primárias de vias, fabricação de argamassas de assentamento e revestimento, fabricação de concretos, fabricação de pré-moldados (blocos, meio-fio, dentre outros), camadas drenantes, etc.

Por exemplo, pesquisas utilizam o agregado de concreto para utilização em novos concretos e apontam bons resultados técnicos e de custo [65-68]. O agregado de cerâmica vermelha foi utilizado para fazer novos tijolos [69], como também se revelou num ingrediente de sucesso de argamassa [70, 71]. A reciclagem de misturas betuminosas, principalmente da demolição de estradas, tem sido exaustivamente estudada [72-74]. Bastos [74] também salienta o emprego do RCD em pavimentação de novas vias. Outros estudos foram realizados objetivando avaliar a viabilidade técnica, como também econômica, da utilização de RCD na produção de materiais de construção como concretos, argamassas, blocos de concreto, elementos prémoldados e em pavimentação [59]. Vieira e colaboradores avaliaram a viabilidade técnica e econômica da utilização de agregados reciclados provenientes de RCD, em concretos [75]. Nesta pesquisa, realizaram uma comparação entre concretos produzidos com agregados naturais e reciclados, substituindo $50 \%$ e $100 \%$ de agregados graúdos e miúdos, em cinco composições. Os resultados da pesquisa indicaram que os agregados reciclados em proporções devidamente dosadas podem melhorar algumas propriedades do concreto, como resistência à compressão e durabilidade [75]. Em algumas cidades brasileiras a reciclagem dos RCD já se tornou realidade. Na cidade de São Paulo desde a década de 1990 os RCD são reciclados; como o uso de entulho para a pavimentação de ruas, e também agregados do concreto. Em Belo Horizonte os resíduos reciclados são utilizados como base de pavimentação e também na produção de argamassas. De acordo com Noronha e colaboradores [76] além das formas de reciclagem utilizadas nas cidades supracitadas o entulho após o processo de moagem pode também ser utilizado na contenção de encostas, calçamento de concreto, blocos de concreto, tubos para a drenagem, entre outros. Segundo Oliveira e colaboradores [77], citado por Oliveira e Mendes [78], em Goiás, $60 \%$ do RCD gerado pode ser reutilizado. O resíduo de construção em Salvador é composto, em sua maior parte, por restos de concreto e argamassa (equivalentes a $53 \%$ ), enquanto $22 \%$ é solo e areia, tendo estes materiais alto potencial de reciclagem para a produção de agregados reciclados [79]. Pinto analisou a utilização do entulho para a produção de argamassa [80]. Este coletou 33 amostras distribuídas pelos depósitos de resíduos da cidade de S. Carlos, SP. Os resíduos foram segregados conforme suas características granulométricas, em 5 classificações. Segundo a pesquisa o material apresentou bons resultados na resistência à compressão das amostras de argamassa com traços de cal, atribuindo estes resultados a dois fatores: à reação pozolânica dos finos reativos dos resíduos, em presença da cal e à maior velocidade de carbonatação. Zordan [81] investigou a utilização do RCD na confecção de concreto, produzindo com o agregado reciclado, concreto com variados traços e razões água/cimento, que foram ensaiados à compressão simples, à abrasão e a permeabilidade, em diferentes estágios de cura. Os resultados obtidos indicaram que o agregado reciclado pode ser incorporado na obtenção de concreto não estrutural, utilizado na infraestrutura urbana. Leite [82] analisou o desempenho de concreto produzido com diferentes proporções de agregado graúdo e miúdo de resíduos da construção civil, analisando ainda 
algumas propriedades físicas dos agregados reciclados. Este considerou a influência de diferentes doses de substituição dos agregados graúdo e miúdo naturais por reciclados e diferentes razões água/cimento sobre as propriedades do concreto no estado fresco e endurecido. Conforme o autor o uso de agregado é perfeitamente viável para a produção de concreto considerando as propriedades mecânicas avaliadas, resistência à compressão, resistência à tração, resistência à tração na flexão e módulo de deformação. Ângulo [83] investigou a viabilidade da utilização dos agregados de RCD reciclados em concretos. A porosidade dos agregados analisados e o comportamento mecânico dos concretos foram relacionados com a soma dos teores de aglomerantes e de cerâmicas vermelhas, por serem os materiais mais porosos presentes nesses agregados. Os agregados inseridos no intervalo de densidade $d>2,2$ possuem teores elevados de rocha e teores baixos de cerâmica vermelha, resultando em concretos com comportamento mecânico semelhante aos agregados naturais analisados. Silva [71] relata os resultados obtidos com a aplicação das orientações da Resolução CONAMA n ${ }^{\circ} 307$ em obras de pequeno porte em Belo Horizonte - MG. Foram escolhidas três novas construções, residencial, comercial e industrial, e uma obra de reforma. Os estudos revelaram uma geração de $684 \mathrm{~kg} / \mathrm{m}^{2}$ na obra de reforma, e nas demais obras a média foi de $97,75 \mathrm{~kg} / \mathrm{m}^{2}$. A correta segregação do material no momento da geração facilitou o seu reaproveitamento na própria obra e sua correta disposição final.

A combinação de RCD com materiais sintéticos alternativos também tem sido pesquisada, tais como borracha de pneus usados e garrafas PET. Esses materiais podem ser utilizados em substituição a materiais granulares naturais em sistemas drenantes. A presença de um geotêxtil envolvendo o material drenante alternativo pode servir como um elemento de filtro para o sistema. A utilização desses materiais alternativos, além de dar uma destinação ambientalmente amigável para tais resíduos, pode representar economias substanciais em regiões onde materiais drenantes convencionais sejam escassos ou caros [84]. Mesmo na Europa, em que existem países com índices de reciclagem acima de 70\% [85], grande parte dessa fração de RCD é destinada para nivelamento de terrenos ou subbases de estradas, raramente retornando ao mercado como agregados para aplicações consideradas nobres, como concretos e argamassas. De acordo com Martinho [86] relativamente à produção e reciclagem, na União Europeia, estima-se que cerca de 130 milhões de ton/ano de RCD são depositados em aterro. Se se considerar uma densidade de 1,0 ton $/ \mathrm{m}^{3}$, será necessário todos os anos um novo aterro com 10 metros de profundidade com uma área de $13 \mathrm{~km}^{2}$, para depositar esta quantidade de resíduos. De acordo com Bernardes e colaboradores [87] os estudos já realizados, de forma geral, mostraram que o primeiro passo para o desenvolvimento de ações visando ao gerenciamento eficaz do RCD é a realização de um diagnóstico local, identificando aspectos referentes a esses resíduos tais como origem, taxa de geração, agentes envolvidos na geração e coleta, destinação final, entre outros, que servem de base para o dimensionamento de ações para o atendimento da resolução vigente. Ainda, podemos dizer que a reciclagem dos RCD será bem sucedida quando for estabelecida uma metodologia que exigirá conhecimentos relacionados a diferentes especializações para o desenvolvimento de um produto destinado a ser um material de construção alternativo.

O programa de gestão ambiental de resíduos em canteiros de obras apresenta muitas vantagens, das quais ocorre a melhoria no ambiente de trabalho, em que, por intermédio da limpeza e organização do canteiro de obra as obras se tornam mais limpas, a empresa que emprega tal gestão apresenta uma imagem positiva no mercado, podendo reduzir os impactos ambientais e sociais e por fim os custos finais serão diminuídos pela redução dos desperdícios de materiais. Mas ainda existem as desvantagens da implantação desse tipo de gestão, pois ainda não há áreas suficientes para o recebimento dos RCD, como também a implantação da gestão ambiental de resíduos exige um alto investimento inicial para por em prática o funcionamento de usinas de reciclagem em locais que a construção civil está crescendo em grandes escalas, como na maioria das cidades brasileiras.

\section{Aplicabilidade de agregados reciclados em misturas asfálticas a quente}

Na pavimentação do tipo concreto asfáltico mais de $90 \%$ em peso do total da mistura corresponde a agregados de várias granulometrias. Como freio à crescente exploração de jazidas para extração de agregados naturais juntamente com a redução de áreas destinadas a aterros e à ampliação de técnicas de reciclagem de resíduos sólidos, diversos pesquisadores têm aplicado agregados reciclados na pavimentação asfáltica, com a finalidade de impulsionar o seu retorno à cadeia da construção civil. Zhu, Wu e Wang [15] citam em seu trabalho misturas asfálticas produzidas a partir de agregados reciclados de concreto [88-90], agregados reciclados de tijolos [91], agregados reciclados de vidro [92], agregados de materiais de construção recuperado [93, 94], agregados de resíduos da construção e demolição $[95,96]$ e agregados provenientes de resíduos de material decorativo de quartzo [97]. Zhu, Wu e Wang [15] estudaram as propriedades do concreto asfáltico produzido com agregados reciclados provenientes de edificações danificadas pelo Terremoto Wenchuan (China). Che, Lin e Wu [98] utilizaram o resíduo de concreto como agregado miúdo e material de enchimento $(<1,8 \mathrm{~mm})$ nas misturas asfálticas, mantendo os agregados graúdos naturais. Mills-Beale e You [88] estudaram as propriedades mecânicas do concreto asfáltico no qual utilizaram o agregado reciclado de concreto em substituição ao agregado natural nas proporções de 25 , 35,50 e $75 \%$ em peso. Já Su e Chen [99] em sua pesquisa, utilizaram agregado reciclado de vidro em substituição ao agregado natural nas proporções $0,5,10$ e $15 \%$ em peso e, Akbulut e Gurer [100] utilizaram agregado proveniente de resíduo de mármore para a produção de concreto asfáltico, ambos os resultados comprovam a viabilidade técnica das 
misturas. Uma pesquisa realizada em 2011 na Espanha, por Pérez e colaboradores [96] utilizou agregado reciclado de RCD em substituição ao agregado graúdo no concreto asfáltico. Os pesquisadores substituíram 20, 40 e $60 \%$ do agregado graúdo natural pelo reciclado. Segundo eles existe uma larga aplicação do agregado reciclado de RCD em camadas de base e sub-base e apenas um pequeno número de investigações tem lidado com este agregado em misturas asfálticas a quente. No Brasil, Frota, Menta e Nunes [101] substituíram o seixo (agregado graúdo) da mistura asfáltica por agregados reciclados produzidos na cidade de Manaus, AM. Realizaram três misturas, sendo uma com seixo e outras duas com agregado reciclado em diferentes proporções (50 e $60 \%$ ), incluindo em todos os casos areia e também cimento Portland como fíler. Notaram que as misturas com agregado reciclado necessitam de uma maior quantidade de ligante, o que já era esperado, pois estes materiais apresentaram maior porosidade do que os convencionais. O teor ótimo de ligante para a mistura apenas com seixo foi de $5,5 \%$, enquanto para as outras misturas contendo agregado reciclado foi de 6,4 e $6,5 \%$, respectivamente, para as misturas com 50 e $60 \%$. Os autores concluíram que as misturas contendo agregado reciclado são tecnicamente viáveis, porém refletem um maior custo em função do maior consumo de ligante. Um artigo apresentado por Ron [102] na $15^{\mathrm{a}}$ Reunião de Pavimentação Urbana em Salvador, consiste em utilizar o RCD reciclado como agregado alternativo em misturas asfálticas, comparando suas características mecânicas e físicas com misturas confeccionadas com agregado convencional. Concluíram que os agregados reciclados estudados apresentam boas características, atendendo às especificações das normas na maioria dos aspectos, porém o teor ótimo de ligante da mistura também foi bastante elevado (7,6\%), quando comparado com misturas que utilizam agregados convencionais, acarretando em custos maiores. Outra pesquisa brasileira, de Silva [103] realizou quatro projetos de mistura à quente contendo agregados de $\mathrm{RCD}$, nas quais utilizou dois tipos de CAP, 30/45 e 50/70 e duas faixas granulométricas "B" e "C" do DNIT, para fins de comparação. Realizou ensaios de caracterização dos agregados e dosagem do concreto asfáltico baseada na metodologia Marshall. Concluiu que, em virtude das suas propriedades físicas e mecânicas, associados aos ligantes, o RCD é adequado para substituir os agregados naturais em camadas betuminosas de vias urbanas de tráfego leve.

A informação de que um armazenamento e uso de RCD possa trazer algum risco ambiental é sempre relevante. $\mathrm{O}$ impacto ambiental pode ocorrer em função da lixiviação ou solubilização de algum outro material que possa estar agregado ao RCD. Por isso, a determinação da composição química do RCD pode apontar como se comportará se este material lixiviar ou solubilizar. No entanto, ensaios de lixiviação e solubilização podem fornecer resultados mais seguros sobre o comportamento destes resíduos, indicando quais tipos de elementos serão liberados e suas possíveis consequências para a qualidade da água. As misturas asfálticas a quente, utilizando como agregado o seixo, possuem grandes vantagens em relação a outras devido a sua elevada resistência mecânica. Paiva e Cartaxo [104] investigaram os possíveis impactos ambientais devido a estas misturas. Segundo os autores os impactos causados são as emissões de Gases de Efeito Estufa bem como Compostos Orgânicos Voláteis, sendo que os operários, responsáveis pela execução do revestimento, submetem-se à inalação destes compostos, comprometendo assim sua saúde. Outra questão quanto o uso de determinados resíduos, como de pneus, é que as temperaturas de compactação giram em torno de $150^{\circ} \mathrm{C}$. A retirada de seixo dos rios, para utilização como agregado, causa impactos como poluição dos rios por combustíveis, morte de vida aquática, desmatamento para a área do material extraído, entre outros. Segundo o que abordamos neste trabalho a solução para minimizar, e muito, estes impactos, é utilização do RCD, como agregado. A utilização deste como agregado alternativo pode trazer um benefício ambiental duplo.

\section{CONCLUSÃO}

Apesar dos mais diferentes dados quanto ao percentual de reaproveitamento do RCD nos mais diferentes países do mundo, pesquisadores, políticos, governos e a própria sociedade estão se voltando cada vez mais para esta realidade, buscando a redução da sua geração e o seu reaproveitamento, com o uso de legislações e das mais diversas aplicabilidades, principalmente, na indústria da construção civil, na forma de agregados reciclados, a fim de promover o seu retorno à cadeia da construção. Os agregados reciclados, além de apresentarem custo de produção inferior ao dos agregados naturais, ainda promovem um "ganho ambiental", uma vez que deixa-se de extrair matéria-prima natural e dá-se um destino final a este tipo de resíduo que tem uma elevada participação no RSU. Porém, o grande empecilho para sua reutilização, é cultural, uma vez que há desconfiança de construtores e clientes quanto ao bom desempenho dos produtos gerados pelo mesmo, e também normativo, uma vez que não há normas que assegurem a sua aceitação no mercado, devido à sua grande heterogeneidade. Políticas e campanhas de conscientização devem inserir tal consciência à sociedade, uma vez que, as ações para alcançar a sustentabilidade devem abranger desde a escala individual, em que cada indivíduo faz o seu papel, até a escala mundial, a partir de governos, organizações, associações e empresas privadas. E, uma forma de assegurar o desempenho e qualidade dos agregados de RCD, é a implantação de controle de qualidade, de forma a reduzir a variabilidade, de acordo com a sua aplicação. Diversas pesquisas já apresentam algumas estratégias para se reduzir a variabilidade, como por exemplo, o uso de dosador para se produzir misturas de agregados reciclados e naturais; britagem somente de alguns tipos de RCD, de acordo com a sua finalidade; classificador espiral para remover a fração orgânica dos agregados; e etc. No Brasil, com a Política Nacional de Resíduos Sólidos, espera-se que cada estado adote medidas de reciclagem de RCD, começando com 
a implantação de usinas de britagem para a produção de agregados. Porém, além de produzir agregados reciclados, devem implantar medidas que garantam a sua utilização. Alguns estados, como por exemplo, Minas Gerais, na cidade de Belo Horizonte, a prefeitura utiliza o RCD reciclado em obras de reestruturação de vilas habitacionais de baixa renda, em obras de manutenção de instalações de limpeza urbana, em pavimentações e em outras obras públicas. Desta forma, é necessário, com urgência, não mais apenas a implantação de leis para uma efetiva redução deste resíduo; mas uma efetiva execução destas medidas, para que não se tenha apenas no papel e sim no cotidiano, de cada brasileiro, essa realidade. De forma que possamos ver, um inimigo, o resíduo da construção e demolição, tornar-se um aliado. No diz respeito às desvantagens da utilização de RCD podemos citar o fato de que ainda não há áreas suficientes para o recebimento dos resíduos, como também a implantação da gestão ambiental de resíduos exige um alto investimento inicial para por em prática o funcionamento de usinas de reciclagem em locais que a construção civil vem crescendo em grande escala, como na maioria das cidades brasileiras. Mais, pode-se citar a utilização de agregados reciclados provenientes de RCD em substituição ao agregado natural no concreto asfáltico. Pois as misturas asfálticas a quente, utilizando como agregado o seixo, possuem grandes vantagens em relação a outras devido a sua elevada resistência mecânica. No entanto, a retirada de seixo dos rios, para utilização como agregado, causa impactos como poluição dos rios por combustíveis, morte de vida aquática, desmatamento para a área do material extraído, entre outros. Segundo o que abordamos neste trabalho a solução para minimizar, e muito, estes impactos, é utilização do RCD, como agregado. A utilização do RCD como agregado alternativo pode trazer um benefício ambiental duplo. Os estudos já realizados, de forma geral, mostraram que o primeiro passo para o desenvolvimento de ações visando ao gerenciamento eficaz do RCD é a realização de um diagnóstico local, identificando aspectos referentes a esses resíduos tais como origem, taxa de geração, agentes envolvidos na geração e coleta, destinação final, composição entre outros, que servem de base para o dimensionamento de ações para o atendimento da resolução vigente.

\section{REFERÊNCIAS}

[1] L. V. Hedre, Economics 10, 3 (2010) 183.

[2] R. C. C. Lintz, A. E. P. G. A. Jacintho, L. L. Pimentel, L. A. Gachet-Barbosa, Revista IBRACON de Estruturas e Materiais 5, 2 (2012) 18.

[3] F. F. Santos, L. U. D. Tambara Júnior, N. F. Cechin, V. L. Almeida, M. A. B. Sousa, Iberoam. J. Ind. Eng. 4, 8 (2012) 1. [4] M. F. N. Santos, R. A. G. Battistelle, C. Y. Hori, P. S. Julioti, GEPROS - Gestão da Produção, Operações e Sistemas, 2 (2011) 57.

[5] A. V. B. Fernandes, J. R. R. Amorim, Cadernos de Graduação - Ciências Exatas e Tecnológicas Unit 2, 1 (2014) 79.

[6] A. E. B. Cabral, V. Schalch, D. C. C. Dal Molin, J. L. D.
Ribeiro, R. S. Ravindrarajah, Cerâmica 55, 336 (2009) 448.

[7] M. C. R. Halmeman, P. C. Souza, A. N. Casarin, Revista Tecnológica, Ed. Especial ENTECA (2009) 203.

[8] C. M. D. F. Marchi, Perspectivas Gestão Conhecimento 1, 2 (2011) 118.

[9] N. Costa Junior, M. Luna, P. Selig, J. Rocha, Eng. Sanit. Ambiental 12, 4 (2007) 446.

[10] M. M. Laruccia, ENIAC Pesquisa 3, 1 (2014) 70.

[11] V. A. Silva, A. L. T. Fernandes, Sociedade e Natureza 24, 2 (2012) 333.

[12] M. E. D. Oliveira, R. J. M. Sales, L. A. S. Oliveira, A. E. B. Cabral, Eng. Sanit. Ambiental 16, 3 (2011) 219.

[13] X. Duran, H. Lenihan, B. O'Regan, Resources, Conservation and Recycling 46, 3 (2006) 302.

[14] L. B. Bernucci, L. M. G. Motta, J. A. P. Ceratti, J. B. Soares, Pavimentação asfáltica: formação básica para engenheiros ( $1^{\text {a }}$ Ed.), PETROBRAS, ABEDA, Rio de Janeiro (2008) 496.

[15] J. Zhu, S. Wu, J. Z. D. Wang, Construc. Build. Mater. 29 (2012) 466.

[16] Y. Huang, R. N. Bird, O. Heidrich, Resources, Conservation Recycling 52, 1 (2007) 58.

[17] PETROBRÁS (2011), disponível em: http://www.brasil. gov.br/noticias/arquivos/2011/01/ 06/petrobras-registranovo-recorde-de-producao-e-venda-de-asfalto-em-2010, acesso em 20/01/2014.

[18] ABRELPE, Panorama dos Resíduos Sólidos no Brasil 2011, disponível em http://www. abrelpe.org.br/Panorama/ panorama2011.pdf. acesso em 20/01/2014.

[19] Portal Brasil, disponível em http://www.portalbrasil. net/historiageral_revolucao industrial.htm, acesso em 02/01/ 2014.

[20] Worldwatch Institute, Estado do Mundo 2013: a sustentabilidade ainda é possivel?, UMA Ed., Salvador (2013) 89p.

[21] E. Ventura, Responsabilidade Social em Instituições Financeiras, Elsevier, Rio de Janeiro, RJ (2009).

[22] G. M. D. Morais, "Diagnóstico da deposição clandestina de Resíduos de Construção e Demolição em bairros periféricos de Uberlândia: Subsídios para uma gestão sustentável", Diss. Mestrado de Engenharia Civil, Universidade Federal de Uberlândia (2006) 201p.

[23] L. A. Karpinsk, A. Pandolfo, R. Reinehr, Ju. Kurek, L. Pandolfo, J. Guimarães, Gestão diferenciada de resíduos da construção civil uma abordagem ambiental EDIPUCRS, Porto Alegre (2009) 163p.

[24] C. J. Kilbert, "Principles of Sustainable Construction", Proceedings of the First International Conference on Sustainable Construction, 6-9 November, Tampa, FL, EUA (1994) 1-9.

[25] A. N. Santos, "Diagnóstico da situação dos resíduos de construção e demolição (RCD) no Município de Petrolina (PE)", Diss. Mestrado de Engenharia Civil, Universidade Católica de Pernambuco (2008) 58p.

[26] A. E. B. Cabral, K. M. V. Moreira, "Manual sobre os Resíduos Sólidos da Construção Civil", Sinduscon-CE (2011) 44p. 
[27] A. E. B. Cabral, "Modelagem de propriedades mecânicas e de durabilidade de concretos produzidos com agregados reciclados, considerando-se a variabilidade do RCD", Tese Dr., Eng. Ambiental, Universidade de S. Paulo (2007) 254p. [28] M. E. D. Oliveira, R. J. M. Sales, L. A. S. Oliveira, A. E. B. Cabral, Eng. Sanit. Ambiental 16, 3 (2011) 219.

[29] R. A. Begun, C. Siwar, J. J. Pereira, A. H. Jaafar, Res. Conserv. Recycling 48, 1 (2006) 86.

[30] V. W. Y. Tam, C. M. Tam, Res. Conserv. Recycling 47, 3 (2006) 209.

[31] K. Rahal, Build. Environm. 42, 1 (2007) 407.

[32] R. Dhir, K. Paine, T. Dyer, Concrete 38, 3 (2004) 25.

[33] A. Coelho, J. D. Brito, Waste Manag. Res. 29, 7 (2011) 739.

[34] J. Xiao, W. Li, Y. Fan, X. Huang, Const. Build. Mater. 31, 6 (2012) 364.

[35] T. R. Araújo, "Aspectos qualitativos e quantitativos dos resíduos de construção e demolição (RCD) na cidade de campina grande", Diss. Mestrado,Universidade Estadual da Paraíba, PB (2011) 82p.

[36] A. T. W. Yu, C. S. Poon, A. Wong, R. Yip, L. Jaillon, Waste Management 33, 1 (2012)138.

[37] L. L. Brasileiro, "Utilização de Agregados Reciclados Provenientes de RCD em Substituição ao Agregado Natural no Concreto Asfáltico", Diss. Mestrado, Universidade Federal do Piauí, PI (2013) 118p.

[38] C. Fischer, M. Werge, "EU as a Recycling Society: Present recycling levels of Municipal Waste and Construction and Demolition Waste in the EU", ETC/SCP, Copenhagen (2009) 73p.

[39] Shanghai Manual: "A Guide for Sustainable Urban Development in the $21^{\text {st }}$ Century", Shanghai, China (2010).

[40] Ministério do Meio Ambiente - MMA, "Projeto internacional de cooperação técnica para a melhoria da gestão ambiental urbana no Brasil" - BRA/OEA/08/001 (2010) 320p.

[41] ABRELPE, "Panorama dos Resíduos Sólidos no Brasil 2013", disponível em: http://www. abrelpe.org.br/ Panorama/panorama2012.pdf, acesso em 10/02/2014.

[42] V. M. John, "Aproveitamento de resíduos sólidos como materiais de construção", in: A. P. Carneiro, I. A. S. Brum, J. C. S. Cassa, (Org), Reciclagem de resíduo para a produção de materiais de construção. Projeto resíduo bom, Caixa Econômica Federal, Salvador, BA(2001)

[43] S. Murakami, H. Izumi, T. Yashiro, S. Ando, T. Hasegawa, "Sustainable building and policy design", Tokyo, Inst. Int. Building Housing, (2002) 16p.

[44] D. M. Schneider, A. Philippi Jr, Ambiente Construído 4, 4 (2004) 21.

[45] S. C. Angulo, C. E. Teixeira, A. L. de Castro, T. P. Nogueira, Eng. Sanit. Amb. 16, 3 (2011) 299.

[46] Instituto Brasileiro de Geografia e Estatística (IBGE), (2010), Ministério do Planejamento, Orçamento e Gestão, Censo 2010. Disponível em: <http://www.ibge.gov.br/ home/ default.php>, acesso em 14/02/2014.

[47] L. Miranda, S. C. Angulo, E. D. Careli, Ambiente Construído 9, 1 (2009) 57.
[48] J. C. Marques Neto, "Estudo da gestão municipal dos resíduos de construção e demolição na Bacia Hidrográfica do Turvo Grande", Tese Dr., Escola de Engenharia de S. Carlos, SP (2009) 629p.

[49] N. C. Silva, R. Malheiros, A. C. Campos, "A reciclagem e o destino final dos resíduos sólidos de construção e demolição produzidos no município de Goiânia", in: IV Cong. Bras. Gestão Amb., Salvador, BA (2013).

[50] Confederação Nacional da Indústria - CNI, Visão da Indústria Brasileira sobre a Gestão de Resíduos Sólidos, Brasília (2014) 218p.

[51] I. A. C. Costa, "Resíduos de Construção e Demolição: fatores determinantes para a sua gestão integrada e sustentável", Diss. Mestrado, Universidade Nova de Lisboa (2014) 58p.

[52] M. B. Leite, "Avaliação de propriedades mecânicas de concretos produzidos com agregados reciclados de resíduos de construção e demolição", Tese Dr., Universidade Federal do Rio Grande do Sul, RS (2001) 270p.

[53] L. H. Pereira, "Construction and Demolition Waste recycling: The Case of the Portuguese Northern Region", Diss. Mestrado, Minho Univ., Portugal (2002) 87p.

[54] A. Coelho, J. Brito, J. Cleaner Prod. 39 (2013) 338.

[55] M. M. Sabai, M. G. D. M. Cox, R. R. Mato, E. L. C. Egmond, J. J. N. Lichtenberg, Res. Cons. Recycling 72 (2013) 9.

[56] F. C. Leite, R. S. Motta, K. L. Vasconcelos, L. Bernucci, Const. Build. Mater. 25, 6 (2011) 2972.

[57] T. P. Pinto, "Metodologia para a gestão diferenciada de resíduos sólidos da construção urbana", Tese Dr., Escola Politécnica, Universidade de S. Paulo, SP (1999) 218p.

[58] E. A. N. Takahashi, "Utilização da escória de alumínio na fabricação de argila expandida", Diss. Mestrado, IPEN, SP (2006) 82p.

[59] P. P. A. Evangelista, D. B. Costa, D. B. Costa, Ambiente Construído 10, 3 (2010) 23.

[60] Instituto Brasileiro de Geografia e Estatística (IBGE). Banco de dados Agregados, Censo 2008, disponível em http://www.ibge.gov.br/home/estatistica/populacao/ condicaodevida/pnsb2008/PNSB_2008.pdf, acesso 14/02/2015.

[61] V. Surgelas, G. F. Marques, C. S. Rodrigues, Educ. Tecnol. 14, 2 (2009) 4.

[62] S. Kitamura, F. A. I. Darwish, R. L. Gaiofatto, REUCP - Rev. Eng. Univ. Cat. Petrópolis 7, 1 (2012) 1.

[65] V. W. Y. Tam, Res. Conserv. Rec. 52, 5 (2008) 821.

[66] N. D. Oikonomou, Cement Concrete Composite 27, 2 (2005) 315.

[67] S. C. Kou, C. S. Poon, D. Chan, "Properties of steam cured recycled aggregate fly ash concrete", in: Proc. RILEM Int. Conf. Use Recycled Mater. Build., Barcelona, Spain (2004) 590.

[68] A. Richardson, Structural Survey 28, 2 (2010) 142.

[69] J. P. Reis, "Incorporação de resíduos industriais em massa cerâmica usada na fabricação de tijolos", Diss. Mestrado, Univ. Est. Santa Catarina, SC (2006) 71p.

[70] J. R. M. C. Silva, "Incorporação de resíduos de barro 
vermelho em argamassas cimentícias", Diss. Mestrado, Inst. Superior Técnico, Lisboa, Portugal (2006).

[71] J. Silva, J. Brito, R. Veiga, Engenharia Civil, Escola Eng. Univ. Minho 28 (2007) 37.

[72] J. Ainchil, A. Burgueño, Proc. RILEM - Int. Conf. Use Recycled Mater. Build., Barcelona, Spain (2004) 322.

[73] A. Baptista, "Bituminous Mixtures Recycled by Heat in a Plant" e "Contribution to Its Study and Application" (in Portuguese), Tese Dr., Univ. Coimbra. Portugal (2006) 165p. [74] G. D. A. Bastos, I. D. A. Bastos, L. Fior, L. Hildebrand, J. A. Cerri, M. S. Araújo, Anais Conf. Lat.-Am. Constr. Sustent., in: X Enc. Nac. Tecnol. Amb. Constr., S. Paulo, 1 (2004) 18.

[75] G. L. Vieira, D. C. C. Dal Molin, Ambiente Construído 4, 4 (2004) 47.

[76] L. Noronha, L. Gasparini, M. Cristina, "Reciclagem e reutilização dos resíduos sólidos da construção civil", FUMEC (2005).

[77] J. C. Oliveira, L. R. Rezende, R. C. Guimarães, J. C. Camapum, A. L. A. Silva, "Evaluation of a flexible pavement executed with recycled aggregates of construction and demolition waste in the municipal district of GoiâniaGoiás", in Int. Symp. Pav. Rec., S. Paulo, SP (2005).

[78] E. G. Oliveira, O. Mendes, "Gerenciamento de resíduos da construção civil e demolição: estudo de caso da Resolução 307 do CONAMA", disponível em: http://www. pucgoias.edu.br/ucg/prope/ cpgss/arquivosupload/36/file/ continua/gerenciamento $\% 20 \mathrm{de} \% 20$ res $\%$ c $3 \% 8$ dduos $\% 20$ da $\% 20$ constru $\%$ c3 $\% 87 \%$ c3\%83o $\% 20$ civil $\% 20$ e $\% 20$ demoli $\%$ c3\%87\%c3\%83o\%20-\%20estudo\%20de $\% 20$ caso\%20da\%20resol_.pdf, acesso em 10/01/2015.

[79] A. S. Lima, A. E. B. Cabral, Eng Sanit Amb. 18, 2 (2013) 169.

[80] F. S. Lima, "Aproveitamento de resíduos de construção na fabricação de argamassa", Diss. Mestrado. UFPB, J. Pessoa, PB (2005).

[81] S. E. Zordan, "A utilização do entulho como agregado, na confecção do concreto", Diss. Mestrado, Fac. Eng. Civil, Universidade Estadual de Campinas, Campinas (1997) 140p. [82] M. B. Leite, "Avaliação de propriedades mecânicas de concretos produzidos com agregados reciclados de resíduos de construção e demolição", Tese Dr., Universidade Federal do Rio Grande do Sul (2001) 270p.

[83] S. C. Ângulo, "Caracterização de agregados de resíduos de construção e demolição reciclados e a influência de suas características no comportamento de concretos", Tese Dr., Universidade de São Paulo (2005) 167p.

[84] E. M. Palmeira, "Soluções de Baixo Custo Envolvendo Geossintéticos e Materiais Alternativos em Obras
Geotécnicas e de Proteção Ambiental", in Congresso Brasileiro de Mecânica dos Solos e Engenharia Geotécnica. Gramado (2010) 16.

[85] S. C. Angulo, V. M. John, C. Ulsen, H. Kahn, A. Mueller, Ambiente Construído 13, 2 (2013) 61.

[86] M. G. Martinho, "Manual Prático para a Gestão de Resíduos", Verlag Dashõfer, Portugal (2009).

[87] A. Bernardes, A. Thomé, P. D. M. Prietto, Á. G. Abreu, Ambiente Construído 8, 3 (2008) 65.

[88] J. Mills-Beale, Z. You, Construc. Building Mater. 24, 3 (2010) 230 .

[89] S. Paranavithana, A. Mohajerani, Res. Cons. Rec. 48, 1 (2006) 1.

[90] W Y. D. Ong, D. D. Sun, D. Lai, Waste Management 27, 2 (2007) 294.

[91] F. M. Khalaf, "Recycling of clay bricks as aggregate in asphalt concrete", in: E. Vázquez, Ch. F. Hendriks, G. M. T. Janssen, Eds., The use of recycled materials in buildings and structures, RILEM (2004) 56.

[92] R. C. West, G. C. Page, K. H. Murphy, "Evaluation of crushed glass in asphalt paving mixtures", in: W. H. Fred, ed., Use of waste materials in hot-mix asphalt, West Conshohocken: ASTM (1993) 117.

[93] D. Shen, J. Du, Const. Building Mater. 18, 6 (2004) 391.

[94] D. Shen, J. Du, J. Mater. Civil Eng. 17, 4 (2005) 400.

[95] A. H. Aljassar, K. B. Al-Fadala, M. A. Ali, J. Mater. Cycles and Waste Manag. 7, 2 (2005) 112.

[96] I. Pérez, A. R. Pasandín, L. Medina, Mater. Design 36 (2012) 840.

[97] M. C. Rubio, F. Moreno, A. Belmonte, Menéndez, Const.. Building Mater. 24, 4 (2010) 610.

[98] M. Chen, J. Lin, S. Wu, Const. Building Mater. 25, 10 (2011) 3909.

[99] N. Su, J. S. Chen, Res. Cons. Recycling 35, 4 (2002) 259.

[100] H. Akbulut, C. Gurer, Build. Environm. 42, 5 (2007) 1921.

[101] C. A. Frota, C. O. Menta, R. F. G. Nunes, in: Reunião de Pavimentação Urbana, Aracaju, SE (2003).

[102] M. B. Ron, M. D. T. Casagrande, A. C. Vale, M. M. Lopes, J. B. Soares, $15^{\text {a }}$ Reunião de Pavimentação Urbana, Salvador, BA (2008).

[103] C. A. R. Silva, "Estudo do agregado reciclado de construção civil em misturas betuminosas para vias urbanas", Diss. Mestrado, Universidade Federal de Ouro Preto, MG (2009).

[104] T. S. Paiva, E. F. Cartaxo, Rev. T\&C Amazônia 2 (2014) 04.

(Rec. 26/07/2014, Rev. 21/02/2015, Ac. 21/03/2015) 